\title{
Synthesis and Characterization of Different Crystalline Calcium Silicate Hydrate: Application for the Removal of Aflatoxin B1 from Aqueous Solution
}

\author{
Lu Zeng, Ligang Yang, Shuping Wang, and Kai Yang \\ College of Materials Science and Engineering, Chongqing University, Chongqing 400044, China \\ Correspondence should be addressed to Lu Zeng; zool@foxmail.com
}

Received 31 December 2013; Accepted 17 February 2014; Published 17 March 2014

Academic Editor: Ming-Guo Ma

Copyright @ 2014 Lu Zeng et al. This is an open access article distributed under the Creative Commons Attribution License, which permits unrestricted use, distribution, and reproduction in any medium, provided the original work is properly cited.

\begin{abstract}
Different crystalline calcium silicate hydrates (CSH) were synthesized under specific hydrothermal conditions and several methods were used to analyze samples. Amorphous calcium silicate hydrates (ACSH) mainly consists of disordered calcium silicate hydrate gel (C-S-H gel) and crystalline calcium silicate hydrates (CCSH) consists of crystallized tobermorite. The adsorption of carcinogenic aflatoxin B1 (AFB1) onto ACSH and CCSH was investigated. The adsorption kinetics was studied using pseudofirst-order and pseudo-second-order kinetic models and intraparticle diffusion model. The pseudo-second-order model provided the best correlation and the intraparticle diffusion controlled the adsorption process of AFB1 onto CCSH. Adsorption isotherm parameters were obtained from Langmuir and Freundlich and the adsorption data fitted to Freundlich much better. Based on the results of $\mathrm{N}_{2}$ adsorption/desorption, adsorption kinetics, and adsorption isotherms, the adsorption mechanism of AFB1 onto CCSH was developed. All results indicate that CCSH has a great potential to be a safe, easy-made, and cost-effective material for the control of AFB1 contamination.
\end{abstract}

\section{Introduction}

The synthesis of calcium silicate hydrate (CSH) under the hydrothermal condition has been extensively studied to manufacture some functional materials. Under different hydrothermal conditions, varieties of $\mathrm{CSH}$ with different structures can be prepared, such as amorphous calcium silicate hydrate $(\mathrm{ACSH})$ and crystalline calcium silicate hydrate (CCSH). ACSH, for example, calcium silicate hydration gel (C-S-H gel), consists of monomer silicate anions with silanol groups [1]. CCSH, for example, tobermorite and xonotlite, is built up of layers of $\mathrm{Ca}$ polyhedra and condensed by wollastonite-type silicate chains on both sides $[2,3]$. CSH is used as functional Materials generally, especially as an adsorbent due to its high specific surface area and a large number of structural sites. In the study of Maeda and Ishida [4], slurries consisting of diatomaceous earth and slaked lime were hydrothermally reacted to synthesize composite C-S-H gel, which has superior dye-adsorption ability. A synthetic adsorbent of $\mathrm{CCSH}$ has been found highly effective for endotoxin removal from aqueous solutions [5]. Katsumata et al. [6] removed natural organic polyelectrolyte (humic and fulvic acids) and their metal complexes by adsorption onto xonotlite. Siauciunas et al. [7] evaluated the effects of $\mathrm{CO}_{2}$ chemisorptions on synthetic tobermorite. Novel technique for phosphorus recovery from aqueous solutions using ACSH was reported recently [8], and also $\mathrm{CCSH}$ with a low $\mathrm{Ca} / \mathrm{Si}$ molar ratio of 0.8-1.0, such as tobermorite [9] and xonotlite [10], has been used for phosphorus recovery. Both of them are beneficial materials for phosphorus recovery and recycling. Moreover, CSH plays an essential role in fixing heavy metals by ways of ion-exchange, adsorption, and chemical restraint. Heavy metals of $\mathrm{Nd}(\mathrm{III}), \mathrm{Zn}(\mathrm{II}), \mathrm{Cd}(\mathrm{II}), \mathrm{Cr}(\mathrm{IV})$, and $\mathrm{Sr}(\mathrm{II})$ uptake by CSH have been reported in the literature [11-15].

Mycotoxins are secondary metabolites of filamentous fungi and naturally occur in food. They represent a large group of different substances produced by different mycotoxigenic species. Aflatoxins are the most common mycotoxins and aflatoxin B1 (AFB1) has been demonstrated to be carcinogenic to animals and humans [16]. At present, the 
TABLE 1: Hydrothermal synthesis conditions.

\begin{tabular}{lcccc}
\hline Samples & $\mathrm{Ca} / \mathrm{Si}$ & $w / s$ & Incubating time $(\mathrm{h})$ & Temperature $\left({ }^{\circ} \mathrm{C}\right)$ \\
\hline $\mathrm{ACSH}$ & 1.0 & 5 & 8 & 120 \\
$\mathrm{CCSH}$ & 1.0 & 10 & 12 & 185 \\
\hline
\end{tabular}

most probable approach for controlling AFB1 contamination is the addition of nonnutritive adsorbent materials to the diet. Minerals such as montmorillonite, sepiolite, zeolite, and kaolinite are the main materials which have been used as the adsorbents of AFB1 [17]. However, these materials are nonrenewable and may be insecure as the natural substance could suffer some contamination (e.g., heavy metals); the US Food and Drug Administration (FDA) stated that "The use of sodium aluminosilicate and hydrated calcium sodium aluminosilicate as binders for mycotoxins is not considered to be generally recognized as safe" [18], so their application is limited in practice. To control AFB1 contamination, it is essential to develop a simple, safe, and cost-effective adsorbent.

Till now, CSH has not been used to bind AFB1 and the structures of $\mathrm{CSH}$ which can impact the adsorption capacity have not been studied too. In this study, different crystalline CSH were prepared under specific hydrothermal conditions and samples were characterized by several methods. The adsorption capacities of CSH for the removal of AFB1 from aqueous solutions were investigated and the adsorption mechanism of AFB1 on CCSH was explained.

\section{Materials and Methods}

2.1. Synthesis and Characterization of CSH. CSH was synthesized in an autoclave (Weihai Chemical Machinery Co. Ltd.). For preparation of $\mathrm{CSH}$, the calcium oxide $(99.99 \% \mathrm{CaO}$, Aladdin Co. Ltd.) and silicon oxide (99.99\% $\mathrm{SiO}_{2}$, Aladdin Co. Ltd) were mixed according to a certain proportion by molar $(\mathrm{Ca} / \mathrm{Si})$. The mixture was added to the water with a certain ratio of water-to-solid by mass (w/s), and then incubated at the set temperatures for several hours to manufacture $\mathrm{ACSH}$ and CCSH; the hydrothermal synthesis conditions are shown in Table 1 [19]. Samples of each synthesis were dried to constant mass in an oven at $80^{\circ} \mathrm{C}$ and then milled to less than $45 \mu \mathrm{m}$ for the adsorption experiments.

ACSH and CCSH were characterized by different methods, including X-ray powder diffraction (XRD), scanning electron microscope (SEM), and $\mathrm{N}_{2}$ adsorption/desorption. XRD was performed on a Rigaku D/max-1200 diffractometer with $\mathrm{CuK} \alpha$ radiation, in the range of $5^{\circ}-70^{\circ} 2 \theta$ and at a step size of $0.02^{\circ}$. SEM micrographs were performed using a TESCAN VEGA II scanning electron microscope, operating at the accelerating voltage of $20 \mathrm{kV}$ and taking images at different magnifications. Brunauer-Emmet-Teller (BET) specific surface area $\left(S_{\mathrm{BET}}\right)$, total pore volumes $\left(V_{\text {total }}\right)$, and average pore diameter $\left(D_{p}\right)$ of the samples before and after adsorption of AFB1 were measured from $\mathrm{N}_{2}$ adsorption/desorption isotherms at $77 \mathrm{~K}$, using an automatic specific surface area measuring equipment (ASAP, 2020, Micromeritics, USA) after a degassing under vacuum for $8 \mathrm{~h}$ at $110^{\circ} \mathrm{C}$.

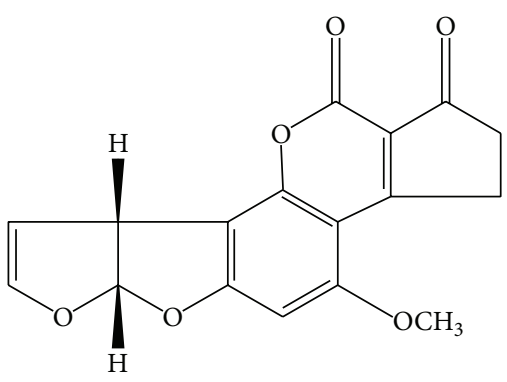

FIgURE 1: Structure of AFB1.

2.2. Adsorption Experiments. The method of enzyme linked immunosorbent assay (ELISA) was used to measure the amount of AFB1. AFB1 was purchased from Sigma-Aldrich Co and ELISA kits were purchased from R-Biopharm Co. The chemical structure of AFB1 is presented in Figure 1 [20]. Firstly, an AFB1 stock solution $\left(2 \mu \mathrm{g} \mathrm{mL}^{-1}\right)$ was prepared, and then $20 \mathrm{mg} \mathrm{CSH}$ was added to a tube that was filled with $10 \mathrm{~mL}$ AFB1 solution, adjusting the solution $\mathrm{pH}$ to 8 by adding $0.1 \mathrm{M}$ phosphate buffer as required. After $2 \mathrm{~h}$ at $28^{\circ} \mathrm{C}$ in a temperature controlled shaking water bath pot at a shaking rate of $120 \mathrm{rpm}$, the tube was centrifuged for $10 \mathrm{~min}$ at $5000 \mathrm{rpm}$ and then the amount of AFB1 remaining in the supernatant layer of dispersion by the method of ELISA was analyzed. The adsorbance of AFB1 was calculated from the difference between initial and equilibrium concentrations of AFB1. In addition, some experiments were performed at solution temperatures of 301,306 , and $311 \mathrm{~K}$ to determine the kinetic parameters with different time intervals. In order to determine adsorption isotherms parameters, experiments were carried out at solution temperatures of $301 \mathrm{~K}$ with different initial concentration which varied from 0.5 to $3 \mu \mathrm{g} \mathrm{mL} L^{-1}$.

\section{Results and Discussion}

\subsection{Characterization}

3.1.1. XRD Characterization. The XRD patterns of ACSH and $\mathrm{CCSH}$ reveal the microstructure variety and comparative XRD patterns of them are presented in Figure 2. As can be seen, the ACSH consists of disordered calcium silicate hydrate (C-S-H) gels with peaks at 3.05, 2.81, and $1.81 \AA$ (corresponding to $29.1,32.2$, and $49.9^{\circ} 2 \theta$, resp.) and unreactive $\mathrm{SiO}_{2}$ from quartz as well due to the short incubating period. The peak of C-S- $\mathrm{H}$ gel at $3.05 \AA$ is strong and broad, but the peaks at 2.81 and $1.81 \AA$ are weak, indicating a low-crystallinity structure [21]. On the contrary, the main composites of CCSH are crystallized tobermorite. The peaks at 11.30, 3.07, 2.97, $2.80,1.84$, and $1.67 \AA$ correspond to the main tobermorite component, especially at $11.30 \AA$ (corresponding to $8^{\circ} 2 \theta$ ) which is strong and sharp, reflecting an ordered and highcrystallinity structure [22]. Moreover, the peaks of quartz disappear, indicating more $\mathrm{SiO}_{2}$ was dissolved in the liquid, which can be attributed to the higher reaction temperature and longer reaction time [19]. 


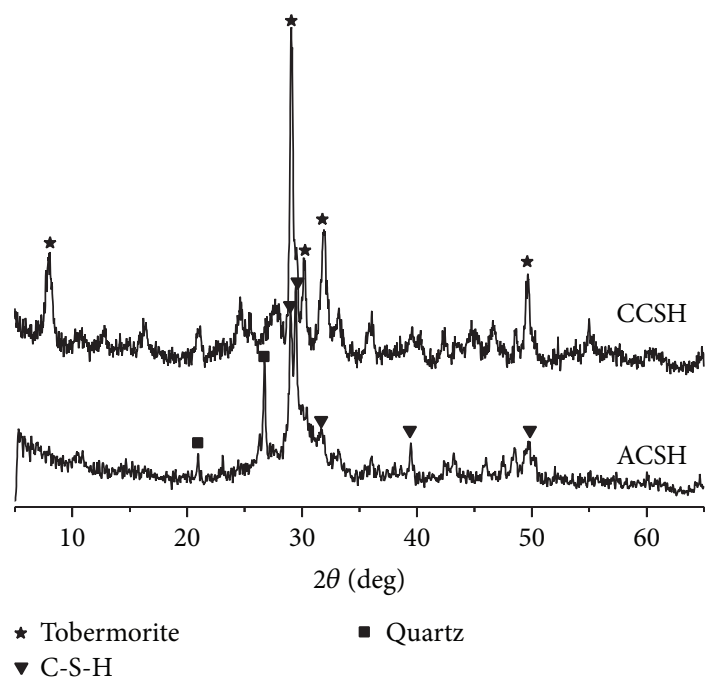

FIGURE 2: XRD patterns of ACSH and CCSH.

3.1.2. SEM Characterization. The SEM micrographs of ACSH and CCSH are shown in Figure 3. The microappearance is different from each other. The ACSH is agglomerated with some irregular flake and fibril. As a certain amount of water is wrapped in the floc, the particle of ACSH is made up of solids and solutions and its appearance is consistent with the typical characteristics of C-S-H gels [23]. Meanwhile, it can be seen that the CCSH consists of the crystals of a plate form which correspond to the microappearance of tobermorite. It is known that $\mathrm{Ca}^{2+}$ and $\mathrm{H}_{2} \mathrm{O}$ insertions exist among tobermorite plates and space among tobermorite plates and insertions are referred to as tubular pores [24]. In addition, a small amount of floccules are observed in the micrograph of $\mathrm{CCSH}$ due to the residual C-S-H gels, which did not turn into tobermorite.

3.1.3. $\mathrm{N}_{2}$ Adsorption/Desorption. The $S_{\mathrm{BET}}, V_{\text {total }}$, and $D_{p}$ of the samples before and after adsorption of AFB1 were measured. Meanwhile, the adsorbance of AFB1 on ACSH and $\mathrm{CCSH}\left(A_{\mathrm{AFB} 1}\right)$ was measured. All of the data were summarized in Table 2. The $\mathrm{N}_{2}$ adsorption/desorption isotherms for samples of original (ACSH and CCSH) and after adsorption of AFB1 (ACSH-AFB1 and CCSH-AFB1) are shown in Figure 4. As can be seen from Figure 4(a), isotherms exhibit Type II behaviors according to the IUPAC classification [25], characteristics of major mesoporous, and a few macroporous adsorbents. Seen from the formed hysteresis loop, the $\mathrm{N}_{2}$ adsorbance in the area of high relative pressure is higher, which fits to the third type of hysteresis loop (H3), indicating slit pores heaped up with flake particles. Meanwhile, compared with ACSH, the $\mathrm{N}_{2}$ adsorbance of $\mathrm{CCSH}$ in the area of high relative pressure is much lower, which may be attributed to pores that formed from layer structure [25]. From Table 2, the $S_{\mathrm{BET}}$ of ACSH is larger than that of $\mathrm{CCSH}$, because disordered ACSH has a structure of three-dimensional networks, while CCSH mainly has twodimensional layer structure [26]. Moreover, it is shown in
TABLE 2: The structure characteristics of samples and adsorbance of AFB1.

\begin{tabular}{lcccc}
\hline Sample & $S_{\text {BET }}\left(\mathrm{m}^{2} \cdot \mathrm{g}^{-1}\right)$ & $V_{\text {total }}\left(\mathrm{cm}^{3} \cdot \mathrm{g}^{-1}\right)$ & $D_{p}(\mathrm{~nm})$ & $A_{\text {AFB1 }}(\mu \mathrm{g} / \mathrm{g})$ \\
\hline ACSH & 89.636 & 0.469 & 20.372 & 274.355 \\
CCSH & 57.343 & 0.247 & 18.924 & 949.261 \\
ACSH-AFB1 & 80.525 & 0.412 & 19.861 & - \\
CCSH-AFB1 & 37.479 & 0.146 & 18.121 & - \\
\hline
\end{tabular}

Figure 4(a) that, in the area of low relative pressure, there is a slight difference between the $\mathrm{N}_{2}$ absorbance of ACSH and that of $\mathrm{CCSH}$. As the relative pressure increased, within the mesohigh relative pressure range and particularly within the high relative pressure range, the $\mathrm{N}_{2}$ adsorbance of ACSH is significantly larger than $\mathrm{CCSH}$, indicating a different pore structure, which is the main reason why the $V_{\text {total }}$ and $D_{p}$ of $\mathrm{ACSH}$ are larger than that of CCSH.

Figure 4(b) presents the $\mathrm{N}_{2}$ adsorption/desorption isotherms of ACSH-AFB1 and CCSH-AFB1. Compared with the original sample, the $S_{\mathrm{BET}}, V_{\text {total }}$, and $D_{p}$ of ACSH-AFB1 slightly decrease and the $\mathrm{N}_{2}$ adsorbance in the area of low relative pressure reduce, approaching closer to the $x$-axis, which can be attributed to micropore filling by the adsorbed AFB1. However, in the area of mesohigh relative pressure, the $\mathrm{N}_{2}$ adsorbance does not show any obvious changes, indicating that the mesoporous does not fill with AFB1. As a mesoporous material, it was concluded that the main way of the adsorption of AFB1 onto ACSH is surface adsorption. On the contrary, the $S_{\mathrm{BET}}, V_{\text {total }}$, and $D_{p}$ of CCSH-AFB1 all are reduced significantly compared with the original sample and the curve approaches more closer to the $x$-axis in various relative pressure ranges. Furthermore, the adsorbance of AFB1 onto CCSH is much higher than that of ACSH. Such a difference is associated with the existing forms of AFB1 molecules in the layer structure of CCSH. There are two reactive mechanisms between $\mathrm{CCSH}$ and organic components [27]: one is the surface adsorption and the other is the interlayer adsorption as organic molecules insert into layers. The adsorbance of interlayer adsorption to the organics is much higher than the surface adsorption. As can be seen from Figure 1, AFB1 belongs to micromolecular organics, after being adsorbed by CCSH; the $S_{\mathrm{BET}}$ of CCSHAFB1 is much smaller than that of the original sample. According to the effect of "pore blockage" when organic molecules fill pores result in the decrease of $S_{\mathrm{BET}}$ [28], it indicates that the interlayer adsorption is the dominant adsorption for the changes of CCSH isotherms before and after adsorption of AFB1. Besides, the hysteresis loop of CCSH-AFB1 fits to the second type of hysteresis loop $(\mathrm{H} 2)$, indicating that "pore blockage" effect changes the pore structure, which forms ink-bottle pore (pores with narrow necks and wide bodies) [25]. Therefore, the interlayer adsorption is the main way for CCSH adsorbing AFB1.

3.2. Adsorption Kinetics. In order to quantify the changes in adsorption with time (Figure 5) and to evaluate kinetic parameters, three models were assessed, including the pseudo-first-order kinetic model, the pseudo-second-order 


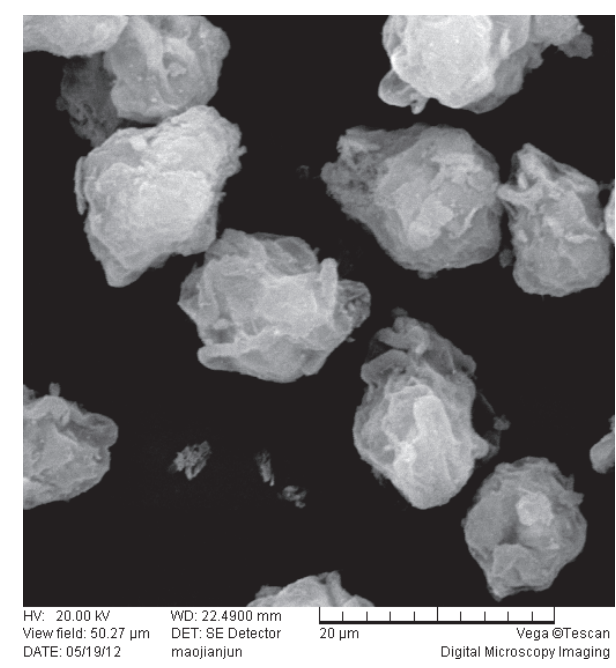

(a)

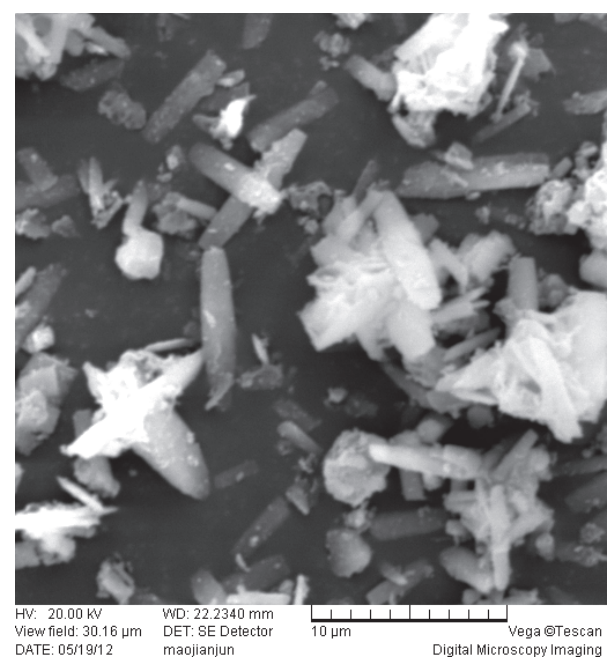

(b)

FIGURE 3: SEM micrographs of ACSH (a) and CCSH (b).

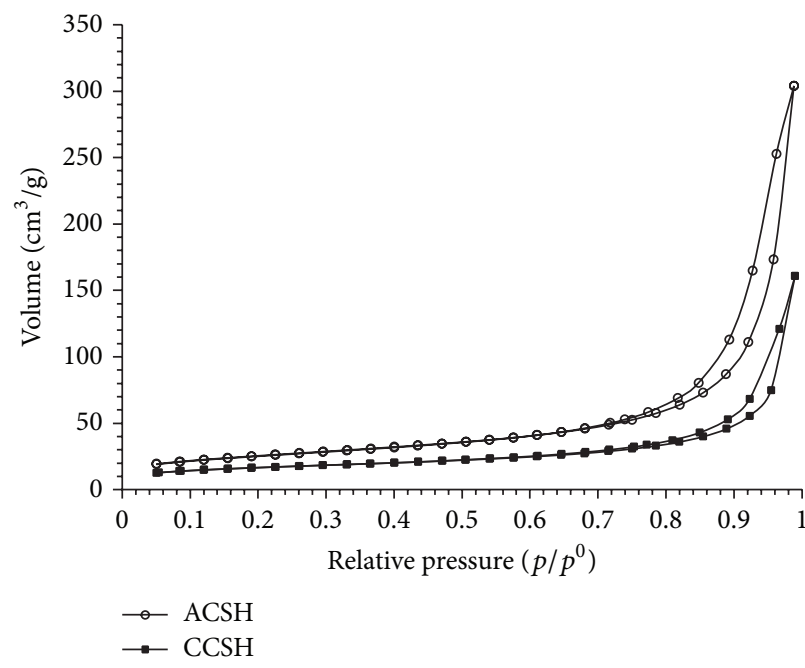

(a)

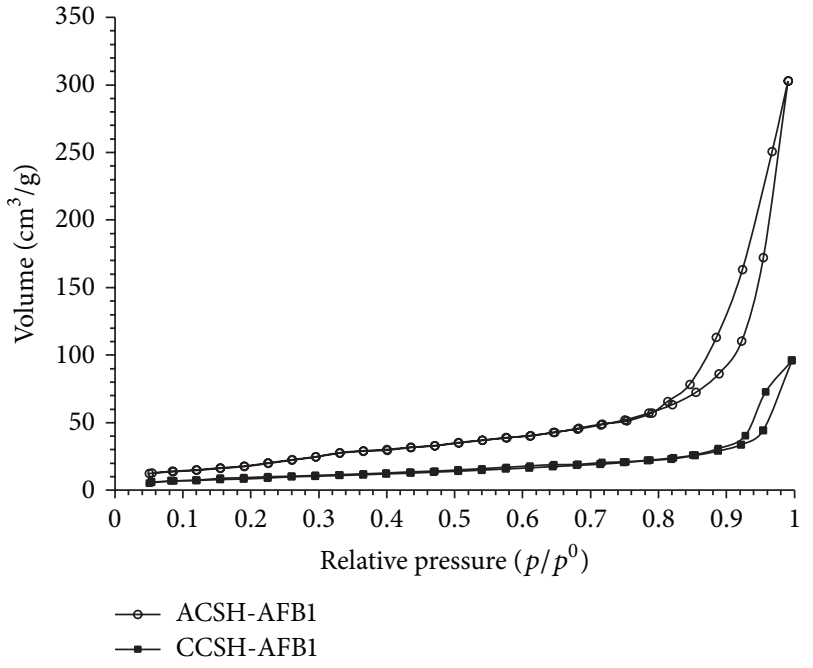

(b)

FIgURE 4: (a) The $\mathrm{N}_{2}$ adsorption-desorption isotherms for ACSH and CCSH. (b) The $\mathrm{N}_{2}$ adsorption-desorption isotherms for ACSH-AFB1 and CCSH-AFB1.

kinetic model, and the intraparticle diffusion model. The pseudo-first-order kinetic model [29] can be expressed as follows:

$$
\lg \left(q_{e}-q_{t}\right)=\lg q_{e}-\frac{k_{1}}{2.303} t
$$

where $q_{e}$ and $q_{t}$ are the amounts of AFB1 adsorbed on CSH $\left(\mu \mathrm{g} \mathrm{g}^{-1}\right)$ at equilibrium and at different time $t(\mathrm{~min})$ and $k_{1}$ $\left(\mathrm{min}^{-1}\right)$ is a rate constant for the adsorption process. Kinetic parameters $\left(q_{e}\right.$ and $\left.k_{1}\right)$ were calculated from the intercept and the slope of the pseudo-first-order straight line.

The pseudo-second-order rate expression [30] can be used to describe adsorption processes in which the reaction rate is proportional to the square of the number of available adsorption sites:

$$
\frac{t}{q_{t}}=\frac{1}{k_{2}\left(q_{e}\right)^{2}}+\frac{1}{q_{e}} t
$$

where $k_{2}\left(\mathrm{~g} \mathrm{mg}^{-1} \mathrm{~min}^{-1}\right)$ is the rate constant and the values of $q_{e}$ and $k_{2}$ were derived from the intercept and slope of a linear plot of $t / q_{t}$ versus $t$.

An intraparticle diffusion model of Weber and Morris [31] is shown as

$$
q_{t}=k_{3} t^{1 / 2}+b
$$

where $b$ represents the intercept and the values of intercept give an idea of the boundary layer thickness which is associated with the boundary layer effect. $k_{3}$ is the intraparticle 


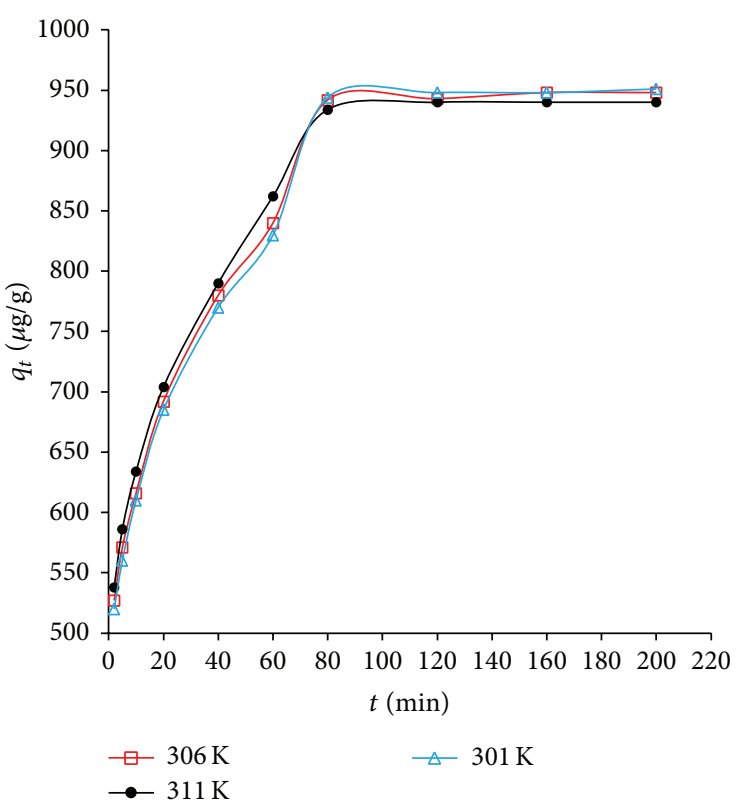

(a)

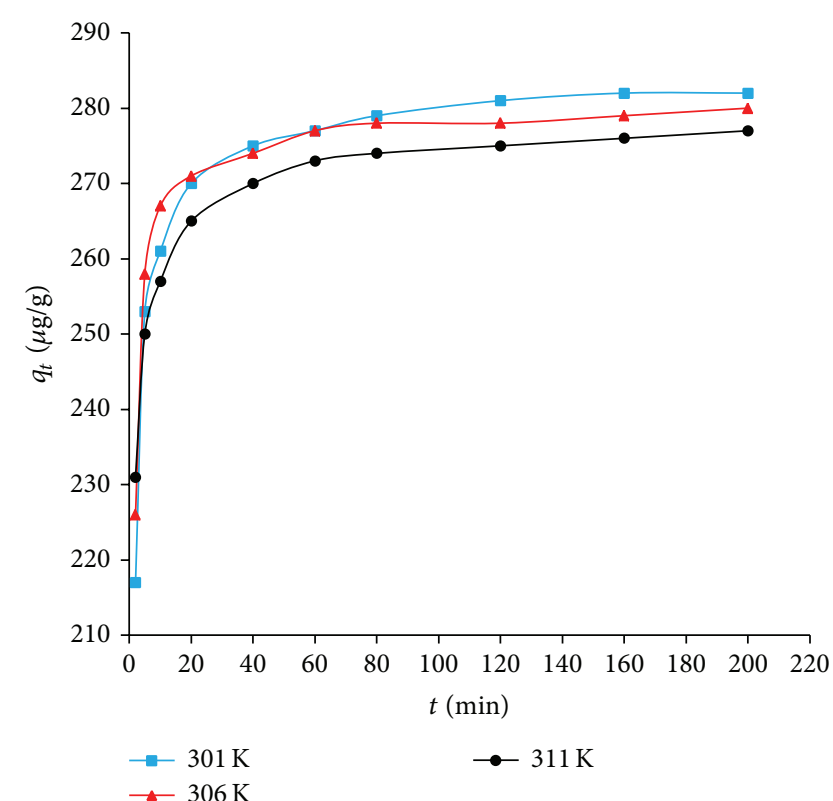

(b)

FIgUre 5: Adsorption kinetics for AFB1 onto CCSH (a) and ACSH (b) at 301, 306, and $311 \mathrm{~K}$.

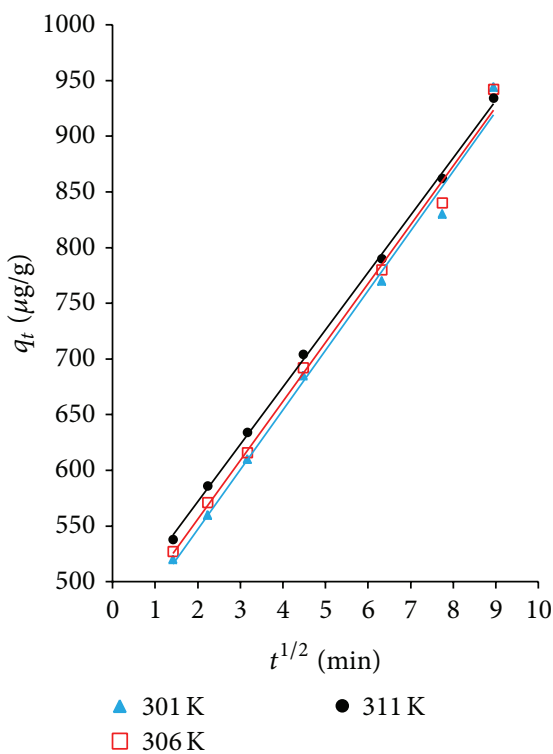

(a)

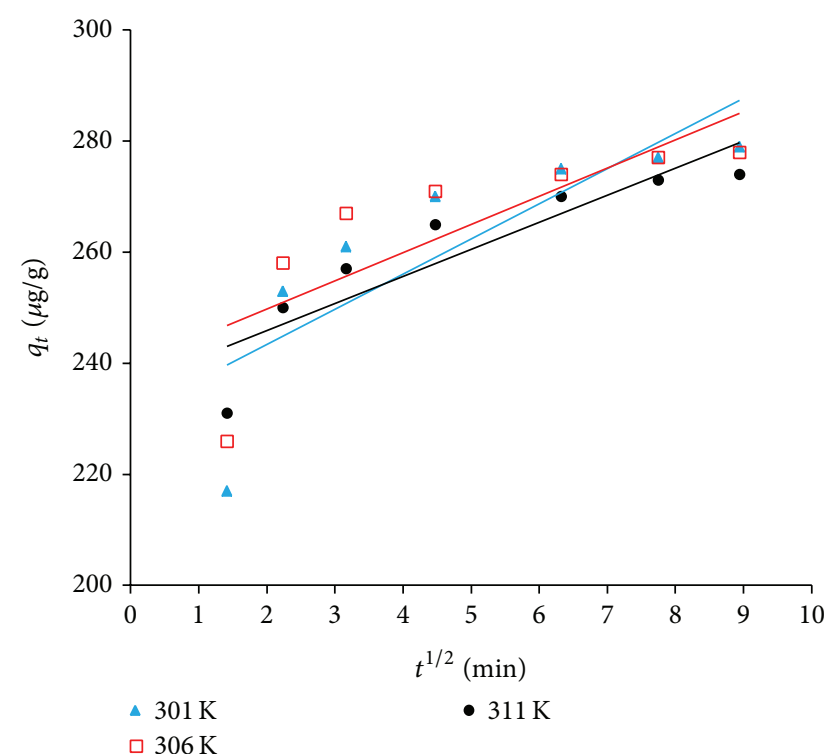

(b)

FIgure 6: Intraparticle diffusion plot for AFB1 onto CCSH (a) and ACSH (b) at 301, 306, and $311 \mathrm{~K}$.

diffusion constant $\left(\mathrm{mg} \mathrm{g}^{-1} \mathrm{~min}^{-1 / 2}\right)$ and the values of $k_{3}$ and $b$ were obtained from the slope and intercept of a linear plot of $q_{t}$ versus $t^{1 / 2}$ (Figure 6).

All parameters and correlation coefficients $\left(R^{2}\right)$ are summarized in Table 3. It can be found that the correlation coefficients of the first-order kinetic model are lower than 0.9 , which are less than the second-order kinetic model. Therefore, the adsorption processes was considered to be explained better by the second-order kinetic model. The values of $q_{e}$ are close to constant with an increase in temperature for adsorption of AFB1 onto ACSH and CCSH. It implies that the temperature does not favor AFB1 adsorption onto ACSH and $\mathrm{CCSH}$ and the type of adsorption can be considered as physisorption. The adsorption rate is an important indicator reflecting the properties of adsorbent that is described by the Weber-Morris equation. Generally, the adsorption processes include three stages. The first is considered as a diffusion of adsorbate through the solution to the external surface of 
TABLE 3: Kinetic parameters for AFB1 adsorption onto ACSH and CCSH at different temperatures.

\begin{tabular}{|c|c|c|c|c|c|c|c|}
\hline \multirow[t]{2}{*}{ Kinetic models } & \multirow[t]{2}{*}{$T(\mathrm{~K})$} & \multicolumn{3}{|c|}{ ACSH } & \multicolumn{3}{|c|}{$\mathrm{CCSH}$} \\
\hline & & $k_{1}\left(\min ^{-1}\right)$ & $q_{e}\left(\mu \mathrm{gg}^{-1}\right)$ & $R^{2}$ & $k_{1}\left(\min ^{-1}\right)$ & $q_{e}\left(\mu \mathrm{gg}^{-1}\right)$ & $R^{2}$ \\
\hline \multirow{3}{*}{ Pseudo-first-order } & 301 & 0.034 & 35.719 & 0.886 & 0.037 & 492.947 & 0.899 \\
\hline & 306 & 0.035 & 27.283 & 0.879 & 0.041 & 541.502 & 0.890 \\
\hline & 311 & 0.025 & 26.528 & 0.893 & 0.046 & 549.035 & 0.866 \\
\hline \multirow{4}{*}{ Pseudo-second-order } & & $k_{2}\left(\mathrm{~g} \mu \mathrm{g}^{-1} \min ^{-1}\right)$ & $q_{e}\left(\mu \mathrm{gg}^{-1}\right)$ & $R^{2}$ & $k_{2}\left(\mathrm{~g} \mu \mathrm{g}^{-1} \mathrm{~min}^{-1}\right)$ & $q_{e}\left(\mu \mathrm{gg}^{-1}\right)$ & $R^{2}$ \\
\hline & 301 & 0.0038 & 285.714 & 0.999 & 0.00017 & 981.448 & 0.998 \\
\hline & 306 & 0.0056 & 277.778 & 0.999 & 0.00018 & 977.279 & 0.998 \\
\hline & 311 & 0.0043 & 277.767 & 0.999 & 0.00021 & 966.428 & 0.998 \\
\hline \multirow{4}{*}{ Intraparticle diffusion } & & $k_{3}\left(\mu \mathrm{gg}^{-1} \min ^{-1 / 2}\right)$ & $b$ & $R^{2}$ & $k_{3}\left(\mu \mathrm{gg}^{-1} \min ^{-1 / 2}\right)$ & $b$ & $R^{2}$ \\
\hline & 301 & 6.317 & 230.76 & 0.684 & 53.534 & 440.40 & 0.991 \\
\hline & 306 & 5.070 & 239.59 & 0.628 & 52.870 & 450.65 & 0.994 \\
\hline & 311 & 4.877 & 236.10 & 0.808 & 51.435 & 469.11 & 0.999 \\
\hline
\end{tabular}

adsorbent or faster adsorption stage. The second describes the gradual layer adsorption stage, where intraparticle diffusion is rate-controlled. The third stage is the final equilibrium stage [32]. It is important to note that the correlation coefficients are lower than 0.81 for ACSH at different temperatures, which suggest a nonlinear relationship. Hence, the adsorption process of AFB1 onto ACSH is not intraparticle diffusion predominantly and three possible adsorption processes may occur. In contrast, the correlation coefficients are higher than 0.99 for CCSH at different temperatures, indicating that the intraparticle diffusion controls the adsorption process, but the intraparticle diffusion curves do not pass through the origin; it indicates that besides intraparticle diffusion, other process may influence the adsorption rate. Moreover, the values of intercept $b$ give an idea about the boundary layer thickness; the larger the intercept, the greater the boundary layer effect [33]. From Table 3, values of b of CCSH are greater than that of ACSH. This means that the greater boundary layer effect is in favor of AFB1 adsorption onto CCSH.

3.3. Adsorption Isotherms. Adsorption isothermal reflects the relationship between adsorption capacity and the concentration of solution at a fixed temperature. Analysis of the isotherm data is important to examine the adsorption mode of AFB1 onto ACSH and $\mathrm{CCSH}$, and the results can be used for the design of more efficient materials to bind AFB1. Therefore, two main models of adsorption isotherm were analyzed, one is Langmuir isotherm [34] and the other is Freundlich isotherm [35], which is widely applied in liquidsolid adsorption system.

The Langmuir isotherm theory assumes monolayer coverage of adsorbate over a homogenous adsorbent surface. In a modified form it can also describe a bilayer deposition. Firstly, the adsorption data were fitted to the linear form of Langmuir adsorption model (see (4)) and obtained the Langmuir isotherm by plotting the particular adsorption $\left(C_{e} / C\right)$ against the equilibrium concentration of $\operatorname{AFB1}\left(C_{e}\right)$. $C_{e}$ is the equilibrium concentration of AFB1 which means the final concentration $(\mu \mathrm{g} / \mathrm{L})$ of AFB1 in the solution after adsorption, $C_{m}$ is the maximum adsorbance $(\mu \mathrm{g} / \mathrm{g}), C$ is the amount of AFB1 being adsorbed by the sorbent at equilibrium
TABLE 4: Isotherm parameters for AFB1 adsorption onto ACSH and CCSH.

\begin{tabular}{lcccccc}
\hline & \multicolumn{3}{c}{ Langmuir } & \multicolumn{3}{c}{ Freundlich } \\
Sample & $\begin{array}{c}C_{m} \\
\left(\mathrm{mg} \mathrm{g}^{-1}\right)\end{array}$ & $\begin{array}{c}K \\
\left(\mathrm{~L} \mathrm{mg}^{-1}\right)\end{array}$ & $R^{2}$ & $K_{f}$ \\
$\left(\mu \mathrm{g} \mathrm{g}^{-1}\right)$ & $n_{f}$ & $R^{2}$ \\
\hline ACSH & -0.333 & -0.284 & 0.807 & 0.005 & 1.483 & 0.996 \\
CCSH & 2.0 & 10.020 & 0.882 & 64.358 & 0.583 & 0.992 \\
\hline
\end{tabular}

$(\mu \mathrm{g} / \mathrm{g})$, and $K$ is a constant related to the adsorption energy. The essential characteristics of the Langmuir isotherm can be expressed in terms of a dimensionless constant separation factor $R_{0}$ which is given by (5). $C_{0}$ is the initial AFB1 concentration $(\mu \mathrm{g} / \mathrm{mL})$. When $R_{0}$ is between 0 and 1 , it indicates a favorable AFB1 adsorption, when $R_{0}$ is higher than 1 , it indicates an unfavorable AFB1 adsorption.

Consider

$$
\begin{gathered}
\frac{C_{e}}{C}=\frac{1}{C_{m} K}+\frac{C_{e}}{C_{m}}, \\
R_{0}=\frac{1}{K C_{0}+1} .
\end{gathered}
$$

The adsorption data were also fitted to the linear form of Freundlich adsorption model which is shown as

$$
\lg C=\lg K_{f}+n_{f} \lg C_{e},
$$

where $K_{f}$ is Freundlich constant related to adsorption intensity and $n_{f}$ is constant as well related to adsorption intensity, $C(\mu \mathrm{g} / \mathrm{g})$ and $C_{e}(\mu \mathrm{g} / \mathrm{L})$ denote adsorbance of AFB1 and equilibrium concentration of AFB1, respectively. Freundlich equation is an exponential variation in site energies and assumes that the adsorbent has a heterogeneous energy distribution of active sites. Theoretically, the Freundlich model is suitable for use with heterogeneous surfaces and with this expression, an infinite amount of adsorption can occur [36].

The absorption isothermal curves of AFB1 onto CCSH and ACSH are shown in Figure 7, and all isotherm values are summarized in Table 4. For Langmuir isotherm shown 


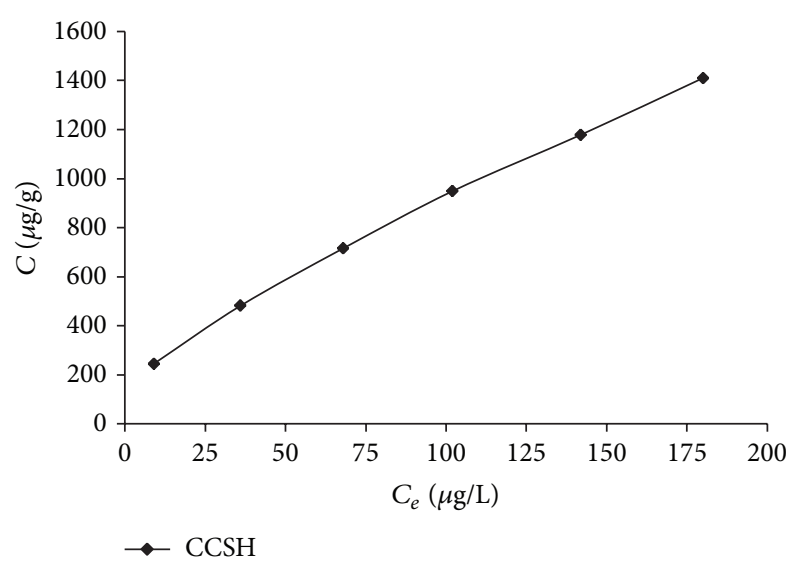

(a)

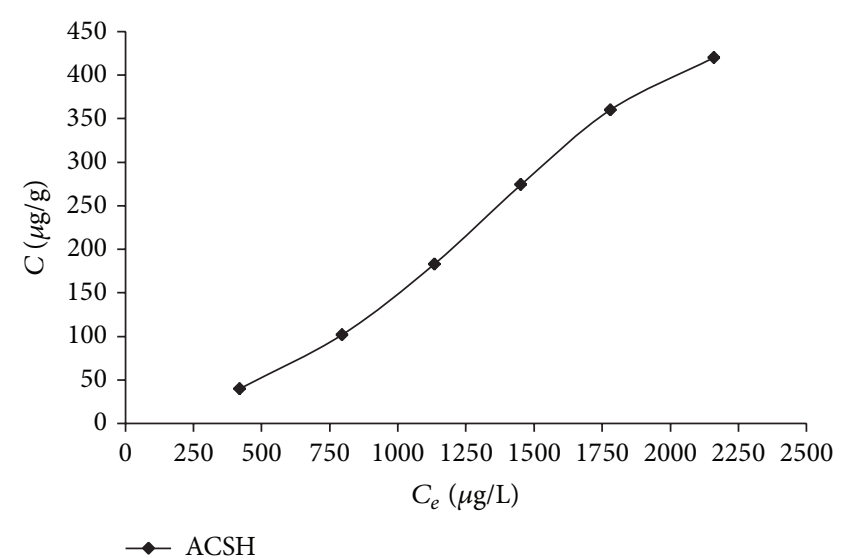

(b)

Figure 7: Adsorption isotherms for AFB1 onto CCSH (a) and ACSH (b) at $301 \mathrm{~K}$.

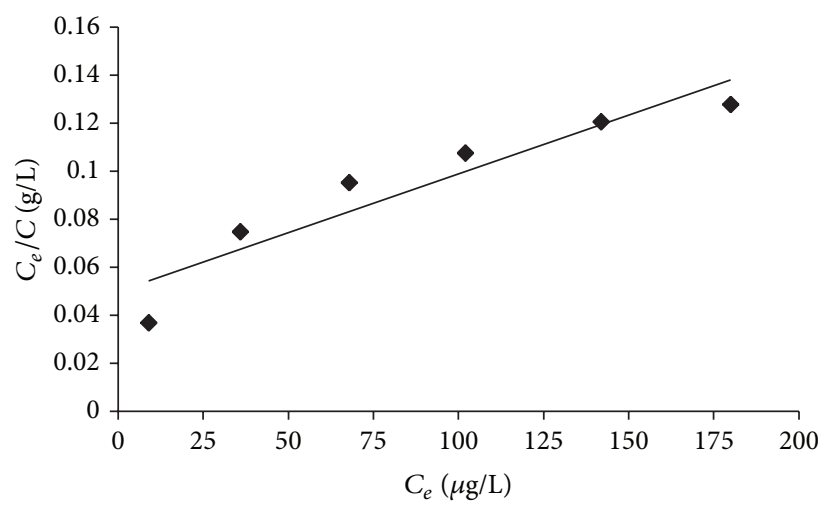

$\bullet \mathrm{CCSH}$

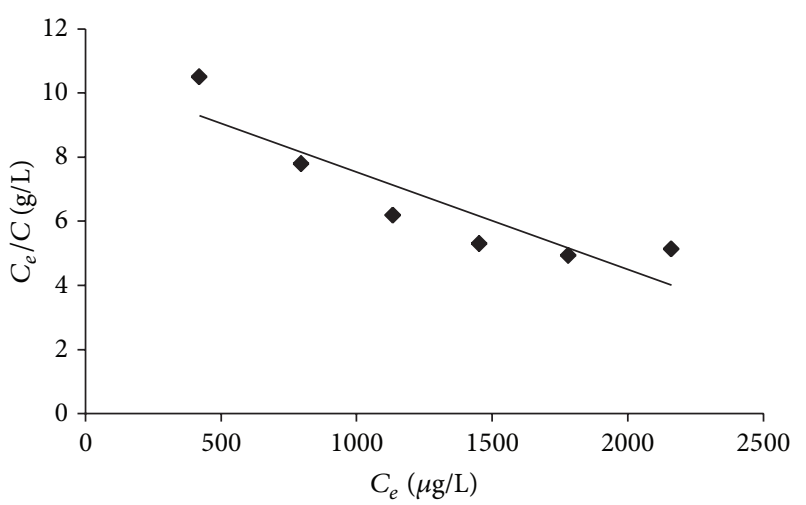

- ACSH

(a)

(b)

Figure 8: Langmuir isotherm for AFB1 onto CCSH (a) and ACSH (b) at $301 \mathrm{~K}$.

in Figure $8, R_{0}$ of $\mathrm{CCSH}$ is between 0.166 and 0.032 , which indicates a favorable adsorption of AFB1 onto CCSH. $R_{0}$ of ACSH is higher than 1, indicating an unfavorable adsorption. Meanwhile, for Freundlich isotherm shown in Figure 9, $n_{f}$ of ACSH at equilibrium is bigger than 1 , as $n_{f}$ is related to adsorption intensity or surface heterogeneity, which ranges between 0 and 1 when a favorable adsorption occurrs. This result indicates that $\mathrm{ACSH}$ has a poor adsorption capacity of AFB1 in the solution. Meanwhile, $n_{f}$ of CCSH is smaller than 1, so this adsorbent is favorable for adsorbing AFB1. Comparing the values of $R^{2}$, it is noted that the Freundlich model yielded a much better fit than the Langmuir model for both of ACSH and CCSH. It can be deduced that the adsorptions of AFB1 on the surface of adsorbents are uneven.

3.4. Adsorption Mechanism. All results above indicate that $\mathrm{CCSH}$ is a suitable adsorbent for the adsorption of AFB1. In order to study it further, the adsorption mechanism of AFB1 onto CCSH was deduced in the following steps and the description is shown in Figure 10.
Firstly, when CSSH and AFB1 were mixed together in solution, the AFB1 molecules transfer from the bulk solution to the CCSH external surface by diffusing through the boundary layer. At this moment, the adsorption of AFB1 onto CCSH was surface adsorption. The main component of CCSH is tobermorite and an important feature of the structure of tobermorite is the cavity between two adjacent building layers, the "interlayer space," which contain water and $\mathrm{Ca}^{2+}$ ions [26]. When $\mathrm{Ca}^{2+}$ ions diffuse into the solution, CCSH is electronegative. For AFB1 molecule, the center of positive charges and that of negative charges does not coincide, which belongs to polar molecule (Figure 1). Through the mode of charge adsorption, polar molecules of AFB1 are adsorbed onto $\mathrm{CCSH}$ with negative charges, while the $\mathrm{Si}-\mathrm{OH}$ on the surface of $\mathrm{CCSH}$ can also bind AFB1 through the hydrogen bonding interaction [37]. This adsorption process has little influence on the adsorption rate.

The second reactive stage is the gradual layer adsorption stage. With the continuous adsorption reaction, the AFB1 molecules diffuse from the external surface into the interlayer of CCSH. While more and more AFB1 molecules diffuse into 


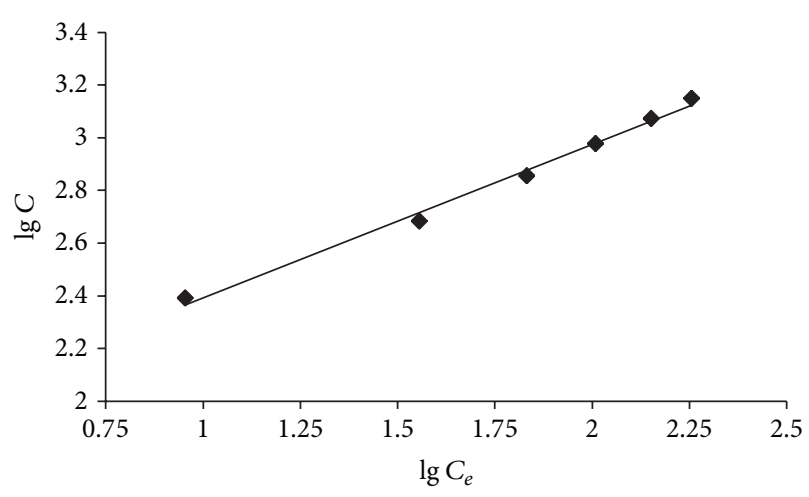

$\bullet \mathrm{CCSH}$

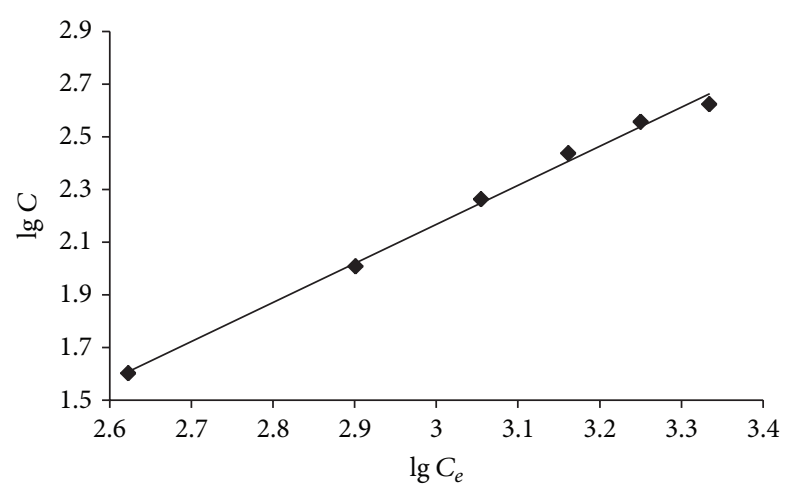

ACSH

(a)

(b)

FIGURE 9: Freundlich isotherm for AFB1 onto CCSH (a) and ACSH (b) at $301 \mathrm{~K}$.

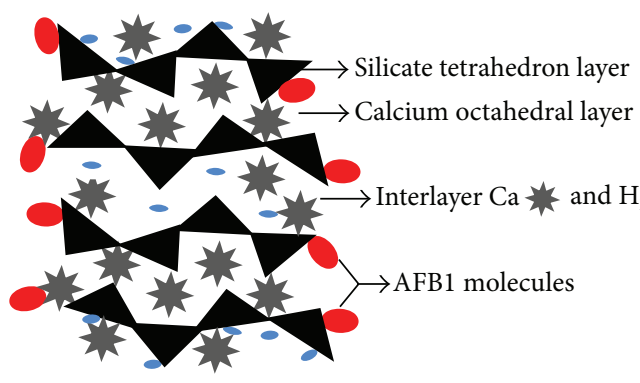

The first stage

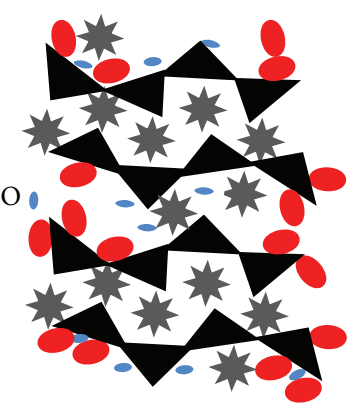

The second stage

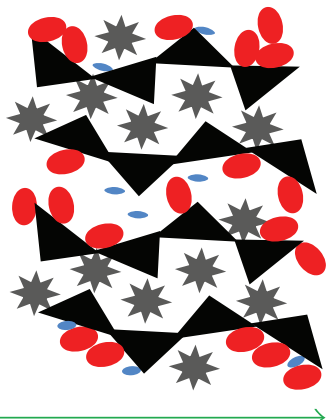

The last stage

Figure 10: Adsorption description of AFB1 onto CCSH.

the interlayer, the "pore blockage" effect occurs which results in the decrease of $S_{\mathrm{BET}}$ and $V_{\text {total }}$. As the adsorption of AFB1 in the interlayer is uneven, several adsorption modes can occur (Fit to Freundlich). It means monolayer adsorption of AFB1 may occur in some locations of interlayer and multilayer adsorption of AFB1 may occur too in some other locations, and in the same way even zero adsorption may exist somewhere. Due to such special adsorption mode, the pore structure is changed and ink-bottle pores are formed. As the adsorption process of AFBl onto CCSH is mainly controlled by intraparticle diffusion, most AFB1 are adsorbed at this stage with the longest reaction time, which controls the adsorption rate (Fit to intraparticle diffusion model). Meanwhile, it is seen that the concentrations of AFB1 and $\mathrm{CCSH}$ can also affect the adsorption rate (fit to the pseudosecond-order kinetic model).

The last stage is the final equilibrium stage. The diffusion of every substance in the system achieves a state of dynamic equilibrium, such as $\mathrm{Ca}^{2+}$ ions, AFB1 molecules, particles of adsorbent, and water molecules. At this stage, the adsorption reaction tends to be stable and the adsorbance of AFB1 on $\mathrm{CCSH}$ reaches the maximum value.

\section{Conclusions}

The results present in this paper demonstrate the characteristics of $\mathrm{CSH}$ and their performance in the adsorption of AFB1 from aqueous solution. It shows that both ACSH and $\mathrm{CCSH}$ can adsorb AFB1, but CCSH is more effective in the adsorption of AFB1. The CSH was characterized by several methods; from the analysis of results, it indicates that a regular layered structure is beneficial for the adsorption of AFB1. CCSH consisting of crystallized tobermorite mainly adsorbs AFB1 into its interlayer, resulting in a higher adsorption of AFB1 and the decrease of $S_{\mathrm{BET}}$ remarkably; it is also the reason for the change of pore structure. For CSH, kinetic studies indicates that the adsorption follows the pseudo-second-order kinetic model $\left(R^{2}>0.99\right)$ and the adsorbance of AFB1 is near constant with an increase in temperature. The adsorption process of AFB1 onto CCSH is intraparticle diffusion $\left(R^{2}>0.99\right)$ predominantly but not for ACSH $\left(R^{2}<0.81\right)$. The data of equilibrium adsorption were fitted to Langmuir and Freundlich equations; Freundlich isotherm model correlates the experimental data better than Langmuir, which implies that adsorptions of AFB1 on the surface of CSH are uneven. Summary analysis of all results, the adsorption mechanism of AFB1 onto $\mathrm{CCSH}$ was deduced by dividing into three stages. As a result, it can be concluded that CCSH has a great potential to be used as an adsorbent for the removal of AFB1 from aqueous solutions, which is safe, easy-made, and cost effective.

\section{Conflict of Interests}

The authors declare no conflict of interests. 


\section{Acknowledgment}

The study was supported by the Fundamental Research Funds for the Central Universities (CDJZR12130052).

\section{References}

[1] Z. H. Wang, L. M. Sun, Y. F. Hou, and E. Z. Tang, "In situ monitoring of C-S-H gel processing by magnetic susceptibility and turbidity measurements," Journal of the American Ceramic Society, vol. 88, no. 7, pp. 1799-1802, 2005.

[2] C. Hejny and T. Armbruster, "Polytypism in xonotlite $\mathrm{Ca}_{6} \mathrm{Si}_{6} \mathrm{O}_{17}(\mathrm{OH})_{2}$," Zeitschrift fur Kristallographie, vol. 216, no. 7, pp. 396-408, 2001.

[3] S. Merlino, E. Bonaccorsi, and T. Armbruster, "The real structure of tobermorite $11 \AA \AA$ : normal and anomalous forms, OD character and polytypic modifications," European Journal of Mineralogy, vol. 13, no. 3, pp. 577-590, 2001.

[4] H. Maeda and E. H. Ishida, "Hydrothermal preparation of diatomaceous earth combined with calcium silicate hydrate gels," Journal of Hazardous Materials, vol. 185, no. 2-3, pp. 858861, 2011.

[5] Q. Wang, J. P. Zhang, T. R. Smith, W. E. Hurst, and T. Sulpizio, "An electrokinetic study on a synthetic adsorbent of crystalline calcium silicate hydrate and its mechanism of endotoxin removal," Colloids and Surfaces B: Biointerfaces, vol. 44, no. 2-3, pp. 110-116, 2005.

[6] H. Katsumata, S. Kaneco, R. Matsuno et al., "Removal of organic polyelectrolytes and their metal complexes by adsorption onto xonotlite," Chemosphere, vol. 52, no. 5, pp. 909-915, 2003.

[7] R. Siauciunas, E. Rupsyte, S. Kitrys, and V. Galeckas, "Influence of tobermorite texture and specific surface area on $\mathrm{CO}_{2}$ chemisorption," Colloids and Surfaces A: Physicochemical and Engineering Aspects, vol. 244, no. 1-3, pp. 197-204, 2004.

[8] K. Okano, M. Uemoto, J. Kagami et al., "Novel technique for phosphorus recovery from aqueous solutions using amorphous calcium silicate hydrates (A-CSHs)," Water Research, vol. 47, no. 7, pp. 2251-2259, 2013.

[9] W. Guan, F. Y. Ji, Q. K. Chen, P. Yan, and L. Pei, "Synthesis and enhanced phosphate recovery property of porous calcium silicate hydrate using polyethyleneglycol as pore-generation agent," Materials, vol. 6, no. 7, pp. 2846-2861, 2013.

[10] X. Chen, H. Kong, D. Wu, X. Wang, and Y. Lin, "Phosphate removal and recovery through crystallization of hydroxyapatite using xonotlite as seed crystal," Journal of Environmental Sciences, vol. 21, no. 5, pp. 575-580, 2009.

[11] P. Mandaliev, R. Dähn, J. Tits, B. Wehrli, and E. Wieland, "EXAFS study of $\mathrm{Nd}$ (III) uptake by amorphous calcium silicate hydrates (C-S-H)," Journal of Colloid and Interface Science, vol. 342, no. 1, pp. 1-7, 2010.

[12] Q. Y. Chen, C. D. Hills, M. Tyrer, I. Slipper, H. G. Shen, and A. Brough, "Characterisation of products of tricalcium silicate hydration in the presence of heavy metals," Journal of Hazardous Materials, vol. 147, no. 3, pp. 817-825, 2007.

[13] O. P. Shrivastava and T. Verma, " $\mathrm{Sr}^{2+}$ Sorption and leach rate studies on synthetic calcium silicate hydroxy hydrate," Advanced Cement Based Materials, vol. 2, no. 3, pp. 119-124, 1995.

[14] M.-P. Pomiès, N. Lequeux, and P. Boch, "Speciation of cadmium in cement-part I. Cd ${ }^{2+}$ uptake by C-S-H," Cement and Concrete Research, vol. 31, no. 4, pp. 563-569, 2001.
[15] C.-K. Lin, J.-N. Chen, and C.-C. Lin, "An NMR, XRD and EDS study of solidification/stabilization of chromium with portland cement and $\mathrm{C}_{3} \mathrm{~S}$," Journal of Hazardous Materials, vol. 56, no. 1-2, pp. 21-34, 1997.

[16] A. Yiannikouris and J.-P. Jouany, "Mycotoxins in feeds and their fate in animals: a review," Animal Research, vol. 51, no. 2, pp. 8199, 2002.

[17] E. Afriyie-Gyawu, Z. Wang, N.-A. Ankrah et al., "NovaSil clay does not affect the concentrations of vitamins $\mathrm{A}$ and $\mathrm{E}$ and nutrient minerals in serum samples from Ghanaians at high risk for aflatoxicosis," Food Additives and Contaminants A: Chemistry, Analysis, Control, Exposure and Risk Assessment, vol. 25, no. 7, pp. 872-884, 2008.

[18] M. Mézes, K. Balogh, and K. Tóth, "Preventive and therapeutic methods against the toxic effects of mycotoxins: a review," Acta Veterinaria Hungarica, vol. 58, no. 1, pp. 1-17, 2010.

[19] S. Shaw, S. M. Clark, and C. M. B. Henderson, "Hydrothermal formation of the calcium silicate hydrates, tobermorite $\left(\mathrm{Ca}_{5} \mathrm{Si}_{6} \mathrm{O}_{16}(\mathrm{OH})_{2} \cdot 4 \mathrm{H}_{2} \mathrm{O}\right)$ and xonotlite $\left(\mathrm{Ca}_{6} \mathrm{Si}_{6} \mathrm{O}_{17}(\mathrm{OH})_{2}\right)$ : an in situ synchrotron study," Chemical Geology, vol. 167, no. 1-2, pp. 129-140, 2000.

[20] R. D. Hartley, B. F. Nesbitt, and J. O'Kelly, “Toxic metabolites of Aspergillus flavus," Nature, vol. 198, no. 4885, pp. 1056-1058, 1963.

[21] A. Stumm, K. Garbev, G. Beuchle, L. Black, P. Stemmermann, and R. Nüesch, "Incorporation of zinc into calcium silicate hydrates, part I: formation of C-S-H(I) with $\mathrm{C} / \mathrm{S}=2 / 3$ and its isochemical counterpart gyrolite," Cement and Concrete Research, vol. 35, no. 9, pp. 1665-1675, 2005.

[22] K. Matsui, J. Kikuma, M. Tsunashima et al., "In situ timeresolved X-ray diffraction of tobermorite formation in autoclaved aerated concrete: influence of silica source reactivity and $\mathrm{Al}$ addition," Cement and Concrete Research, vol. 41, no. 5, pp. 510-519, 2011.

[23] W. Nocuò-Wczelik, "Effect of $\mathrm{Na}$ and $\mathrm{Al}$ on the phase composition and morphology of autoclaved calcium silicate hydrates," Cement and Concrete Research, vol. 29, no. 11, pp. 1759-1767, 1999.

[24] H. Youssef, D. Ibrahim, S. Komarneni, and K. J. D. Mackenzie, "Synthesis of $11 \AA$ Al-substituted tobermorite from trachyte rock by hydrothermal treatment," Ceramics International, vol. 36, no. 1, pp. 203-209, 2010.

[25] K. S. W. Sing, "Reporting physisorption data for gas/solid systems with special reference to the determination of surface area and porosity (Recommendations 1984)," Pure and Applied Chemistry, vol. 57, no. 4, pp. 603-619, 1985.

[26] P. Mandaliev, R. Dähn, J. Tits, B. Wehrli, and E. Wieland, "EXAFS study of Nd(III) uptake by amorphous calcium silicate hydrates (C-S-H)," Journal of Colloid and Interface Science, vol. 342, no. 1, pp. 1-7, 2010.

[27] A. Popova, G. Geoffroy, M.-F. Renou-Gonnord, P. Faucon, and E. Gartner, "Interactions between polymeric dispersants and calcium silicate hydrates," Journal of the American Ceramic Society, vol. 83, no. 10, pp. 2556-2560, 2000.

[28] W. Zhang, J. Ye, Y. Wang, H. Wang, Y. Wang, and Y. Li, "Pore structure and surface fractal characteristics of calcium silicate hydrates contained organic macromolecule," Journal of the Chinese Ceramic Society, vol. 34, no. 12, pp. 1497-1502, 2006.

[29] S. Lagergren, "Zur theorie der sogenannten adsorption gelöter stoffe," Kungliga Svenska Vetenskapsakademiens. Handlingar, vol. 24, no. 4, pp. 1-39, 1898. 
[30] Y. S. Ho and G. McKay, "Pseudo-second order model for sorption processes," Process Biochemistry, vol. 34, no. 5, pp. 451$465,1999$.

[31] W. J. Weber and J. C. Morris, "Kinetics of adsorption on carbon from solutions," Journal of the Sanitary Engineering Division, vol. 89, no. 2, pp. 31-60, 1963.

[32] N. Rauf, S. S. Tahir, J. H. Kang, and Y. S. Chang, "Equilibrium, thermodynamics and kinetics studies for the removal of alpha and beta endosulfan by adsorption onto bentonite clay," Chemical Engineering Journal, vol. 192, pp. 369-376, 2012.

[33] L. Zeng, S. P. Wang, X. Q. Peng, J. Q. Geng, C. Y. Chen, and M. $\mathrm{Li}$, "Al-Fe PILC preparation, characterization and its potential adsorption capacity for aflatoxin B1," Applied Clay Science, vol. 83-84, pp. 231-237, 2013.

[34] I. Langmuir, "The constitution and fundamental properties of solids and liquids. Part I. Solids," The Journal of the American Chemical Society, vol. 38, no. 11, pp. 2221-2295, 1916.

[35] H. M. F. Freundlich, "Über die adsorption in löungen," Zeitschrift fur Physikalische Chemie, vol. 57, pp. 385-470, 1906.

[36] B. Ismail, S. T. Hussain, and S. Akram, "Adsorption of methylene blue onto spinel magnesium aluminate nanoparticles: adsorption isotherms, kinetic and thermodynamic studies," Chemical Engineering Journal, vol. 219, pp. 395-402, 2013.

[37] J. J. Beaudoin, B. Patarachao, L. Raki, and R. Alizadeh, "Adsorption of methylene blue as a descriptor of C-S-H nanostructure," Cement and Concrete Composites, vol. 33, no. 2, pp. 246-250, 2011. 

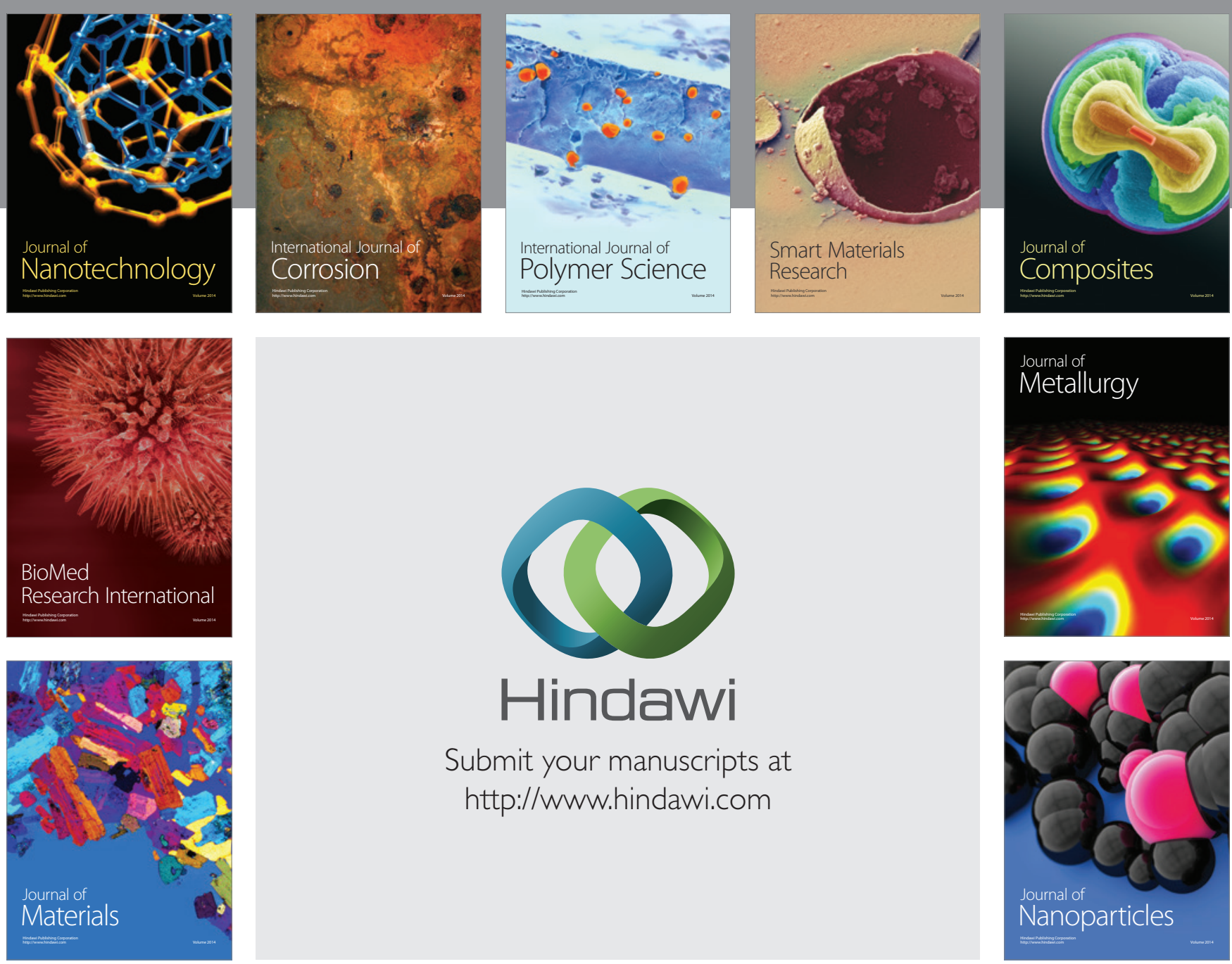

Submit your manuscripts at http://www.hindawi.com
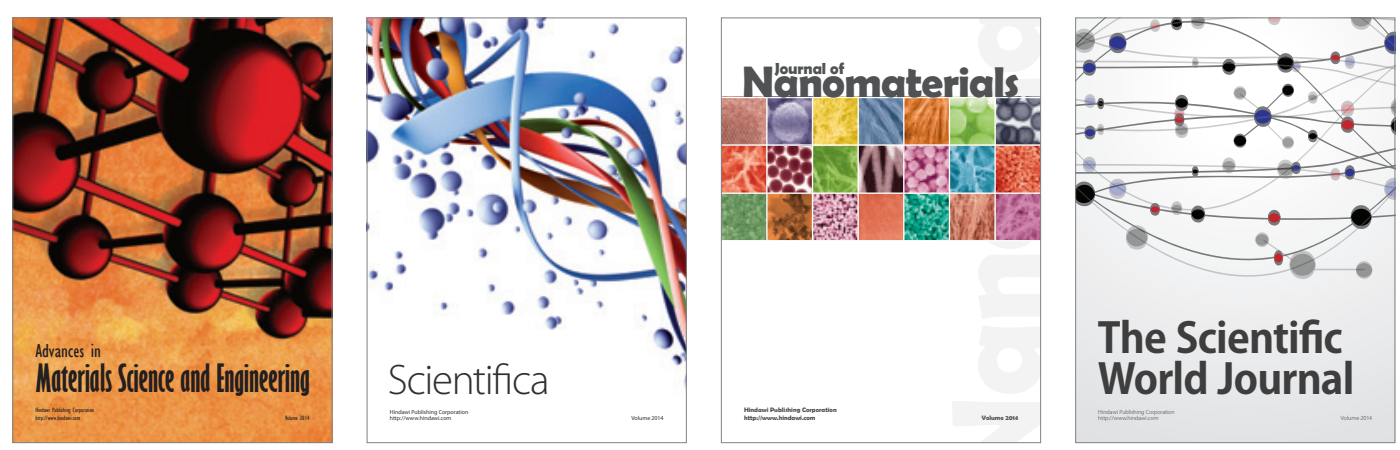

\section{The Scientific World Journal}
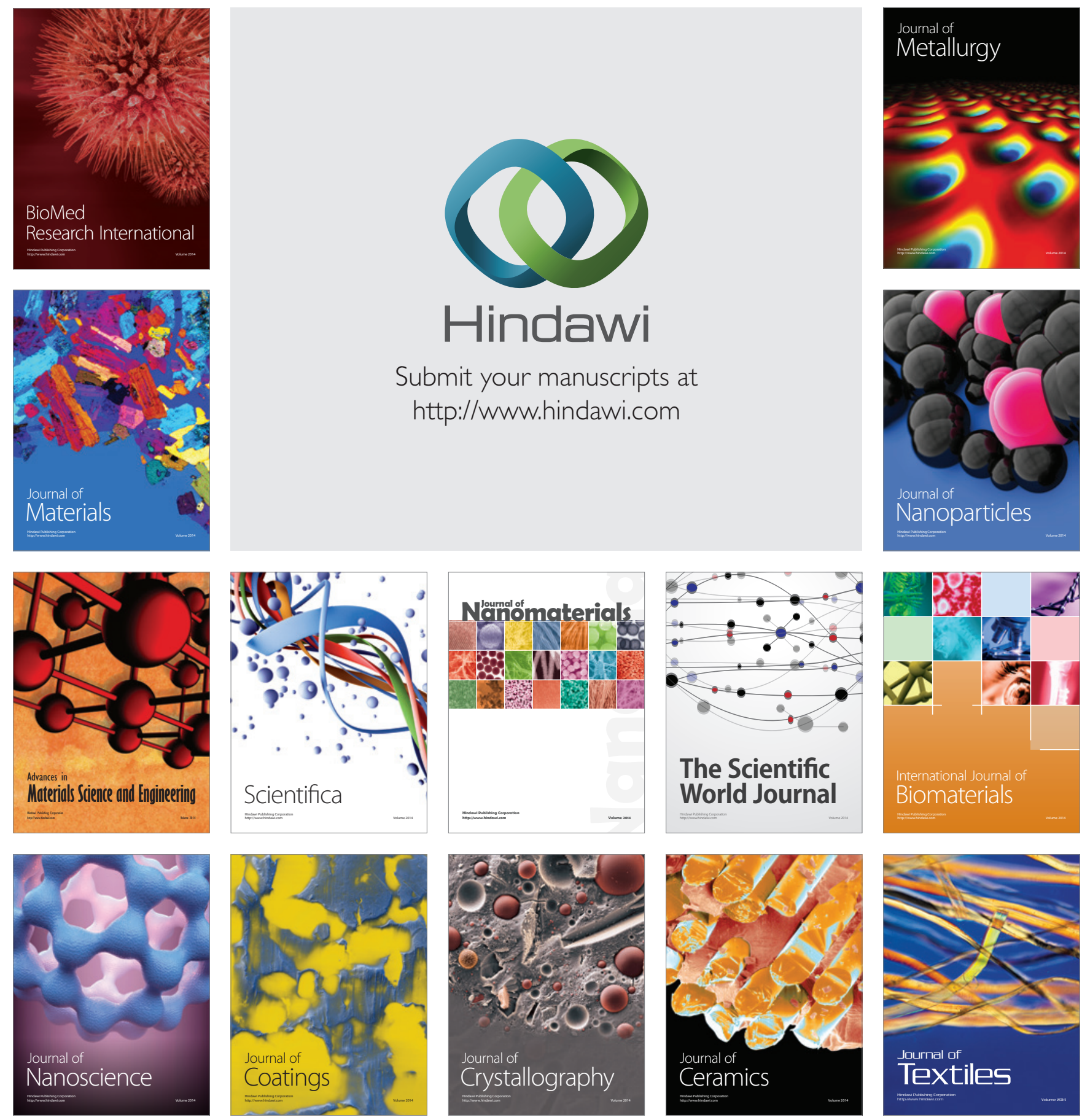